\title{
RELIGIÓN Y POLÍTICA EN EL LEVIATÁN DE HOBBES
}

\author{
Jorge Alfonso \\ Universidad de Tarapacá \\ Arica-Chile \\ jalfonso@uta.cl
}

\begin{abstract}
ResUmen / ABSTRACT
El artículo analiza la relación entre religión y política en el Leviatán de Hobbes. Primero, se recuerda la idea de religión en Hobbes y su lugar en su filosofía política; esto es, que sea una teología política. En segundo lugar, se examina la conformación de una república cristiana y su fundamento en las Escrituras. En tercer lugar, se explica por qué la mejor forma de gobierno para Hobbes es el absolutismo de los soberanos en la tierra, similar al de Dios en los Cielos. Para terminar con una crítica a la recepción del cristianismo en Hobbes.

Palabras clave: Política, reino, Escrituras, poder absoluto, Leviatán.
\end{abstract}

\section{Religion and Politics in Hobbes's Leviathan}

The articles analyses the relationship between religion and politics in Hobbes's Leviathan. In the first place, the idea of religion and its place in his political philosophy is determined. In the second place, the institution of a Christian commonwealth and is foundation in the Scriptures is analyzed. In the third place, the reason why the best form of government for Hobbes is the absolute power of sovereigns on earth similar to God in Heavens. To finish with a criticism of Hobbes's reception of Christianity.

KEYWORDS: Politics, kingdom, Scripture, absolute power, Leviathan.

$\mathrm{RA}$ Thomas Hobbes al referirse al origen de la religión en el Leviatán $(1651)^{1}$ deja establecida la superioridad del cristianismo sobre las religiones paganas. Sin embargo, para quienes examinan este tema como una parte de su filosofía política, la interpretación del capítulo es al menos sospechosa o discutible, ya que no se tiene claridad respecto a si se trata de una fundamentación religiosa de la política, de un complemento que faltaba para que la visión del tema fuera completa ${ }^{2}$ o simplemente de una lectura política del fenómeno religioso. Por

Thomas Hobbes, The English Works of Thomas Hobbes III. Sir William Molesworth, Bart (ed.). Scientia Verlag Aalen, Germany, 1966. I: 12.

2 Habiendo adelantado, Hobbes, la publicación del Leviatán (1651), que vendría después del De Corpore, y el De Cive, para intervenir en las luchas político-religiosas de la Inglaterra de Cromwell, resulta interesante lo que afirma el autor en una carta respecto a los aspectos 
eso vamos a analizar algunas afirmaciones al respecto con el ánimo de evaluarlas sobre la base de lo que los textos dicen. Lo haremos en el siguiente orden: I.- Origen y naturaleza de la religión; II.- De la religión a una república cristina; III.- El Libro de Job como clave hermenéutica; IV.- Conclusión.

\section{I.- Origen y naturaleza de la religión}

F. C. Hood (1964) reconoce que en EW. III, 12, Hobbes expone con claridad el hecho de que la religión es un fenómeno solamente humano y que tiene su origen en la curiosidad sobre el origen de los fenómenos naturales. Además, que el temor ante un futuro incierto genera ansiedad y el deseo de saber o conocer los designios divinos es natural. Posteriormente, la reflexión sobre las causas por parte de los antiguos filósofos los llevaría hacia una idea de un Dios causa prima, el Dios de los filósofos. Sin embargo, F. C. Hood parece titubear sobre este origen puramente intelectual, "científico", si se quiere de la religión, aduciendo que el mismo Hobbes reconoce que la ciencia la poseen solo unos pocos hombres, lo que a su vez lleva a Hobbes a afirmar que "Religión is neither superstitious fancies nor philosophic speculations as to the nature of God, but law"'. Éste sería el propósito de la religión, aunque Hobbes hace una distinción útil para nuestros propósitos. Al referirse a "la semilla de la religión" sostiene que

...these seeds have receive culture from two sorts of men. One sort have been they that have nourished, and ordered them, according to their own invention. The other have done it, by God's commandments, and direction: both sorts have done it, with the purpose to make those men that relied on them, the more apt to obedience, laws, peace, charity, and civil society (Hobbes, EW III. 12: 99).

Los dos tipos de hombres cristianos o paganos coinciden en el fin político de la religión. Así, para los paganos, según Hobbes, se trata de los deberes de los súbditos para con

físicos y metafísicos de su obra. Aclara Hobbes: "La razón por la cual me he tardado tanto en la primera sección de mis Elements (De Corpore) es en parte, flojera, pero en la mayor parte el hecho que encuentro difícil explicar lo que quiero decir a mi entera satisfacción.

Porque estoy buscando alcanzar en metafísica y física, lo que espero haber logrado en teoría moral, de manera tal, de no dar lugar a ninguna crítica que puedan hacer en mi contra".

Letter 42, Hobbes to Samuel Sorbiere, from Paris, 22 May/1 June 1646, Thomas Hobbes. The Correspondence. Noel Malcolm (ed.) Vol. 1 (Oxford: Oxford Claredon Press, 1994, 133). Lo que implica que los aspectos metafísicos y físicos, aunque fueran publicados después de los políticos, forman parte de los fundamentos del sistema hobbesiano, de su philosophia prima. Hacemos esta advertencia para que no se crea que su política pueda entenderse sin recurrir a fundamentos metafísicos, cristianos en este caso.

3 La religión no es ni fantasía superticiosa, ni especulación filosófica sobre la naturaleza de Dios, sino que ley (F. C. Hood. (1964). The Divine Politics of Thomas Hobbes. Oxford: Claredon Press, 70). 
su rey terrenal y, para los cristianos, los deberes para con Dios. En el primer caso se trata de los gentiles y su política humana y la formación de sus republicas y leyes; en el segundo caso se trata para Hobbes de una política divina y es el caso de Abraham, Moisés y Jesucristo "...by whom have been derived unto us the laws of the kingdom of God” (Hobbes, EW III, 12, 99) ${ }^{4}$.

F. C. Hood, no lo sabemos bien, no lo podemos apreciar, parece querer morigerar esta afirmación del fin político que tendría el invento de la religión haciendo ver que Hobbes sugiere que las religiones y las repúblicas nacieron juntas, lo cual es cierto a la luz del texto ya clásico de Fustel de Coulanges (1864/2012) La Ciudad Antigua. En verdad según este autor la religión es el origen de la política. Fue de las creencias religiosas que se pasó a las instituciones, como la creencia en una otra vida después de la muerte llevó a normar los entierros y en caso de herejía a negar los entierros de quienes en ellas incurrían. Pero no queda muy claro si el tema se refiere a la superioridad del cristianismo como religión revelada y al Dios cristiano como dictando normas a los hombres, lo que está de acuerdo con lo que Hobbes dice. Pero no podemos dejar de hacer ver que, aun en este caso, la función política de la religión para Hobbes parece ser la de hacer a los hombre más obedientes a sus gobernantes, ya que para F. C. Hood la interpretación hobbesiana es religión $=$ ley.

El problema es que habría que buscar en las Escrituras el fundamento último de la política cristiana para poder deducir la función política del cristianismo, lo que es altamente discutible en términos escriturales y doctrinales: ¿Qué queda del escándalo ante los judíos? ¿Qué queda de la doctrina de las dos espadas? El judaísmo siempre consideró la Biblia un texto religioso y político, a la vez; fue un escándalo que Jesús no pareciera querer establecer una relación estrecha entre religión y política, y menos con una política particular, la judía, pero la ampliación de su mensaje a toda la humanidad lo hacía imposible. Querer reducir su mensaje a la sola obediencia al poder político es minimizar la idea del pacto original o alianza, como también lo es querer reducir la doctrina de las dos espadas a una sola, la de la ley, lo cual sería reducir todo poder a uno solo, el político, y toda virtud, a la obediencia ${ }^{5}$.

La relación entre religión y política en Hobbes siempre ha sido tema de debate. De leer el $E W$ III, 12 se podría pensar que la presencia de afirmaciones escriturales que definen un tipo de política paternalista, teocrática y mesiánica es suficiente para demostrar que la política hobbesiana no solo imita la bíblica sino que la establece como fundamento de su política. Pero aun así hay quienes piensan que Hobbes no es sincero, que se aprovecha de la religión y la convierte en un instrumento del Estado para lograr la sumisión de muchos a unos pocos, o simplemente la sumisión de todos

$4 \quad$ “... por medio los cuales nos han sido derivadas las leyes del reino de Dios" (Hobbes, $E W$ III. 12, 99).

$5 \quad$ Cfr.D. J.Elazar, "Hobbes Confronts Scripture”. Jewish Political Sudies Review, Vol. 4, N 2, Fall 1992, 3-2; \& J.Ratzinger. Benedicto XVI. Jesús de Nazaret (Bogotá: Planeta, 2007). 
a un gobernante absoluto ${ }^{6}$. Ahora bien, el tema nunca se planteó en Hobbes como algo tan general como la relación entre religión y política, sino más bien en términos más particulares; en términos de derecho o en términos morales. Por ejemplo, en el caso de los individuos: ¿quién debe gobernar? Pero siempre sus planteamientos han dado origen a una serie de discusiones sobre el racionalismo naturalista de Hobbes, su ateísmo metodológico, o su afán de probar el origen del Estado sin emplear premisas metafísicas de carácter sobrenatural. Y la naturaleza conflictiva de estos temas vuelve a aparecer aquí. Una de las últimas polémicas sobre la relación entre ética y razón en Hobbes es la iniciada por John Deigh (1996), quien distingue entre una interpretación que fundamenta la ética hobbesiana en su psicología y en el deseo último de todo hombre de preservar su vida, lo que ha dado origen a la tesis del egoísmo hobbesiano; y otra, la de los que ven en la ética de Hobbes una deontología de carácter absoluto basada en Dios y sus mandamientos de tipo kantiano. Deigh insiste en que el sistema de Hobbes es más bien formal, producto de una deducción a partir de definiciones correctas; $\mathrm{M}$. Murphy (2000), en cambio, discute la validez de la tesis de Deigh sobre la base de la consideración de textos que implican algo más que un puro sistema deductivo, formal, y se hace cargo de los resultados basados en la experiencia, haciendo ver que Hobbes está consciente de que en las ciencias prácticas no se puede esperar la aplicación estricta de un método geométrico, y que el problema es que las leyes naturales, que serían el fundamento de la ética, no describen sino que prescriben. A su vez K. Hoekstra (2003) se inserta en la polémica haciendo ver que Deigh peca por querer hacer ver a Hobbes como un formalista, que luego es algo inconsecuente con este mismo ideal, y critica a Murphy por una idea incorrecta sobre la razón en Hobbes, haciendo notar que Hobbes considera, a la vez, natural a la razón y, a su vez, ligada al deseo de sobrevivencia, conciliando así a los formalistas con los psicologistas.

Todo este largo comentario lo hacemos para hacer ver un problema que F. C. Hood ya había advertido: Hobbes nunca estableció explícitamente cómo el soberano deriva su autoridad de Dios (F.C. Hood 137-138) y que si el gobierno es soberano, lo es por comisión, como lo insinúa Hobbes en su versión latina del Leviatán, pero en ninguna parte esta comisión está explícita. Pensamos que el tema sigue abierto y que si bien Jesús mismo sugirió dar al César lo del César y a Dios lo de Dios, y san Pablo advirtió que todo poder viene de Dios y a él está ordenado, lo que hace Hobbes parece, a primera vista, perfectamente ortodoxo y basado en las Escrituras; sin embargo, una

6 Una postura totalmente opuesta a este enfoque contractualista de la relación entre Dios y los hombres es la que da a conocer W. Allen en su artículo "The Two and the Many: Or, Love and Polítics", (Modern Age 2004) en el cual es el amor el lazo que debiera unir a los hombres para permitir no que unos pocos pudieran tener poder sobre muchos, sino para que pudiera haber una democracia que, aun reconociendo las diferencias, permitiera el acomodo de las personas a un orden político. En todo caso, es interesante poder contrastar la visión hobbesiana de la relación entre religión y política donde, extrañamente, hablando del cristianismo, no es el amor, sino el temor a la muerte violenta en estado de naturaleza la que permite tal acomodo. 
vez que se tiene una visión más detallada, la forma de plantear los temas por parte del pensador inglés no deja claro si lo que él hace corresponde a una continuidad de pensamiento entre el lenguaje bíblico y el suyo -una continuidad ontológica-, mediante la cual seguimos haciendo lo que en la Biblia hacían los pueblos, una imitación de los gobernantes terrenos del pacto entre Dios y los hombres, una deducción a partir de sentencias bíblicas formalizadas como los principios de una política cristiana. De ahí los problemas para acotar bien lo que Hobbes hace, problema que no podemos ni siquiera intentar resolver aquí, pero que esperamos, siquiera, poder plantear mejor ${ }^{7}$.

\section{II. - De la religión a una república cristiana}

Una vez que Hobbes ha establecido su idea de religión, y probado o, más bien mostrado, la superioridad del cristianismo como religión revelada, superior a la religión natural de los gentiles, y habiendo establecido que la religión en este caso estaba al servicio de la política, ha llegado, según él, el momento de proponer la idea de una república cristiana, la cual si siguiera el camino tradicional, tendría que ceñirse a la doctrina de las dos espadas, es decir, a la separación de los dos poderes, el espiritual y el temporal, doctrina que proviene de transformar las aspiraciones místicas de san Agustín de llevar la ciudad de los hombres hacia la ciudad de Dios en una doctrina política aplicable al diario vivir ${ }^{8}$.

Pero aun con todo eso, Hobbes no cree en la efectiva separación de los dos poderes. Para él, el poder o es uno, total y absoluto, o simplemente no existe como tal; si los hombres ven dos poderes donde solo existe uno, es porque sufren de una suerte de defecto visual que los hace ver doble. Ciertamente, debemos reconocer que la

7 Siendo el intento de Hobbes, en el mejor de los casos, una imitación del pacto de Dios con los judíos, habría que advertir que contractualismo no es federalismo, y que la idea judía es mucho más amplia que la hobbesiana. Al respecto habría que prestar más atención a la Biblia como un texto político y al federalismo judío como paradigma político (Cfr. D. J.Elazar, "Covenant as a Political Concept", The Covenant Tradition in Politics, Volumen 1, Chapter 1, Transactio Publishers, Jan, 1997, \& “Covenant and Community," Judaism, New York: Fall 2000. Vol. 49, Iss. 4, 387-399.

$8 \quad$ "El primer texto en el que se expresa el agustinismo político es la carta que Gelasio I (Papa de 490 a 496) dirige al emperador Atanasio. Después de distinguir los dos organismos mediante los que el mundo es soberanamente gobernado, la sagrada autoridad de los pontifices y el poder real, Gelasio precisa, inequivocamente: ... la responsabilidad de los sacerdotes es de tal modo la mayor que deberán dar cuenta al Señor, en el Juicio Final, de los mismos reyes. En efecto, tú sabes, hijo clementísimo, que aunque gobiernes al género humano gracias a tu dignidad, bajas sin embargo, la cabeza con respeto ante los prelados de las cosas divinas; tú esperas de ellos, al recibir los sacramentos celestiales, los medios de tu salvación; y aun disponiendo de ellos sabes también que hay que someterse al orden religioso más bien que dirigirlo". Citado por J. Touchard en Historia de las Ideas Políticas (Madrid: Tecnos 1987, 108). 
experiencia histórica parece confirmar que los dos poderes, el espiritual y el temporal, tienden a confundirse- no obstante si el poder fueran uno solo no habría discordia o tensión entre ambos poderes, pero como de hecho las hay, pareciera que sí hay dos poderes en pugna.

Pero sigamos examinando la progresiva secularización del cristianismo que nuestro filósofo inicia en la época moderna. Al principio, al cristianismo le convino llegar a ser la Iglesia no solo católica y apostólica, sino que además romana por sobre todas las cosas; este hecho fue lo que le permitió constituirse en una institución del imperio -alcanzar el poder, diría Hobbes- y tener así la posibilidad real de llevar adelante su misión evangélica. Sin embargo, tampoco se puede desconocer que el cristianismo inicia una nueva época histórica, con un nuevo ethos; los hombres que sinceramente se convirtieron al cristianismo, vieron en él no solo una posibilidad de salvación eterna, sino una moral digna de ser aplicada a los asuntos humanos, lo que a su vez trajo como consecuencia que los poderes terrenales se interesaran por obtener el apoyo moral del cristianismo para su legitimación y sentirse apoyados no solo in foro externo con una moral ciudadana -conveniente en una época de crisis política-, sino, además, in foro interno en la conciencia de cada uno: El poder establecido se sometía así a las normas de la política cristiana9.

En verdad, ésta sería la situación vista desde un punto de vista puramente ideal, porque lo que sucedió fue que el poder político, que el mismo cristianismo siempre ha considerado como algo perteneciente a la ciudad del diablo y no a la ciudad de Dios, pudo corromper muchas veces no solo a las autoridades políticas, sino que también a las eclesiásticas, hasta tal punto, que el ideal cristiano de los dos poderes puede ser considerado, sobre todo en la época de Hobbes, como una utopía irrealizable o como una mala concepción del mensaje cristiano ${ }^{10}$. Ante esta situación, nuestro autor, parece creer posible una reformulación de la doctrina política cristiana, y esto es lo que va a hacer cuando trate de la Christian Common-wealth (de la República Cristiana), 3, 3242 de los Principles of Christian Politics (de los Principios de la Política Cristiana). Pero antes de empezar nuestro análisis, quisiéramos volver a los capítulos anteriores, a $E$ W III, 30- 31 of Common-wealth, del Estado, de donde vamos a traer a colación algunas ideas que servirán de puente para el tema de la política cristiana.

En las partes finales de EW III, 31 of the kingdom of God by nature (del reino de Dios por naturaleza), antes de referirse a la república cristiana, Hobbes se refiere al gobierno de Dios sobre los hombres, primero por medio de la ley natural, y después

9 Cfr. M. García-Pelayo, El Reino de Dios, Arquetipo Político (Madrid: Revista de Occidente, 1959).

10 "El imperio cristiano intentó muy pronto convertir la fe en un factor político de unificación imperial. El reino de Cristo debía, pues, tomar la forma de un reino político y de su esplendor. La debilidad de la fe, la debilidad terrena de Jesucristo debía ser sostenida por el poder político y militar. En el curso de los siglos, bajo distintas formas, ha existido esta tentación de asegurar la fe a través del poder, y la fe ha corrido siempre el riesgo de ser sofocada precisamente por el abrazo del poder" (J. Ratzinger, op. cit. 64-65). 
por medio de la política que se deriva de ella. Vuelve a recordar, nuestro autor, que la situación en el estado de naturaleza es de total libertad, y por lo mismo de anarquía, ya que es justamente esta libertad total la causa de la guerra de todos contra todos. Son, precisamente, las normas que la razón prescribe para salir de tal estado las que constituyen las leyes. Leyes que en la versión de Hobbes requieren de un poder absoluto que se imponga a todos los hombres para evitar el retorno a la anarquía. Por eso mismo comienza afirmando:

That the condition of mere nature, that is to say, of absolute liberty, such as theirs, that neither are sovereigns, nor subjects, is anarchy, and the conditions of war: that the precepts, by which men are guided to avoid that condition, are the laws of nature: that a commonwealth, without a sovereign power, is but a word without substance, and cannot stand: that subjects owe to sovereign, simple obedience, in all things wherein their obedience is not repugnant to the laws of God ... (Hobbes, EW III 12, 343).

En esta breve formulación de su doctrina, Hobbes establece dos principios muy importantes para la comprensión de ésta: $1^{\circ}$ las leyes de naturaleza son los preceptos por medio de los cuales los hombres son guiados para evitar el estado de naturaleza, y $2^{\circ}$ una república sin gobernante es una palabra sin sustancia. Ya antes incluso, al final del capítulo que precede a esta afirmación, Hobbes había subrayado, además, con toda claridad, que las leyes naturales son leyes porque provienen de Dios y Dios las impone con su poder irresistible; por eso es muy importante que un soberano cristiano las siga, y así se asegura, primero, de estar haciendo la voluntad de Dios; y segundo, de que sus súbditos saben que deben obedecerle porque su poder está establecido por Dios para el cuidado de la comunidad. Ahora bien, el soberano, al instituir la comunidad, la instituye $\mathrm{y}$ también, la representa. La secuencia es clara, y nadie mejor que el mismo Hobbes para explicarla partiendo de la noción de una nación soberana como una persona que puede tomar decisiones en nombre de sus representados.

Un soberano cristiano representa a Dios en esta tierra, es su vicario ${ }^{11}$, y debe respetar la ley natural, porque si no lo hace, no solo no será un gobernante legítimo, sino que no estará cumpliendo su papel en la creación ${ }^{12}$. Por eso es tan importante saber cuáles son estas leyes de Dios por naturaleza y que es el primer tema que plantea

11 El problema de cuál es la relación entre Dios y los reyes no es fácil de resolver: ¿Donación? Si bien todo poder viene de Dios, no hay una cita bíblica directa al respecto; ¿Vicariato? Tampoco está claro; ¿Delegación de poderes? Si lo hay parece ser solo para los apóstoles, y en cuestiones espirituales; ¿Continuidad histórica? Habría que mostrar una genealogía que se extendiera de los judíos a los ingleses, cosa que algunos contemporáneos de Hobbes intentaron, pero que éste no lo intenta; ¿Imitación? Podría ser, aunque Hobbes tendría que avenirse a emular un ideal que, como tal, no siempre es posible de realizar por completo y que ciertamente es más amplio que la reducida visón del cristianismo de Thomas Hobbes.

12 Para una comprensión del tema del origen de la teología política, ver la obra de D'ors "Teología Política: una revisión del problema" (Revista de estudios políticos, No 205, 1976, 
Hobbes, y que debemos revisar antes de plantearnos el problema de la república cristiana. Hobbes señala que si un hombre común no conoce las leyes de Dios, no sabe si lo que ordena su soberano es legítimo, o si debe obedecerle o no, y en tal caso puede verse enfrentado al dilema de cómo ser un buen cristiano y un buen ciudadano a la vez. De esta manera, en el caso de llegar a vivir bajo el poder de un rey pagano, demasiada obediencia al César ofende a Dios, pero, a su vez, demasiada obediencia a Dios puede ofender al César. Conocer la ley de Dios es entonces relevante para determinar cuándo es legítimo obedecer al soberano. Sin embargo, sabemos que, en el contexto hobbesiano, Dios es incognoscible y no podemos conocer sus planes, y, por lo tanto, no nos queda más que honrarlo, es decir, reconocerle su poder. Reconocerle su poder es entonces lo verdaderamente importante, porque es su poder lo que hace que su voluntad sea ley, y es, por último, su voluntad, no su razón, que no podemos conocer, lo que importa. $\mathrm{Su}$ irresistible poder, en consecuencia, se ejerce tanto en la tierra como en el cielo, y por lo mismo la única forma de conocer sus leyes en este mundo es ir a las Escrituras y prestar atención a lo que Dios dice directamente, o por la boca de algún profeta $u$ hombre santo, o por lo que el mismo Jesús dice. Por eso, las razones que Hobbes va a dar sobre la naturaleza de las leyes de Dios son todas tomadas de las Escrituras como fuente de la filosofía cristiana respecto al poder.

Comienza Hobbes en $E W$ 2: 31, recordando que ya ha demostrado que en el estado de naturaleza, donde no hay soberanos ni súbditos, el resultado es la anarquía total y una guerra de todos contra todos, y que los preceptos por los cuales los hombres son conducidos fuera de esta condición son las leyes de naturaleza, entendidas a la manera hobbesiana como prescripciones racionales para mantenerse vivos lo hombres y no ir como ovejas entre los lobos (cosa que ya no suena como muy cristiana), y que una república sin soberanos es una palabra sin substancia y un gobierno que no se sostiene en el tiempo. En consecuencia, habiendo advertido Hobbes que los súbditos le deben obediencia a su soberano en tanto éste no se aparte de la palabra de Dios, el tema ahora es saber cuál es este poder de Dios y cuáles son sus leyes, para lo cual habrá que buscar en las Escrituras lo que dicen respecto el Reino de Dios. Lo primero que el pensador inglés se pregunta es cuáles son los súbditos en el reino de Dios y acude a dos citas bíblicas: God is king, let the earth rejoice (Dios es rey, que la tierra se regocije), de acuerdo al salmista (Salmo xcix.1) y God is king, though the nations be angry; and he that sitteth on the cherubims, though, the earth be moved (Dios es rey, aunque las naciones se enojen, y él se sienta sobre los querubines, aunque la tierra se mueva), del mismo salmo. Con lo que queda claro que los hombres, les guste o no, están todos sometidos a Dios, ya que además "By denying the existence, or providence of God, men may shake off their ease, but not their yoke" (Hobbes, EW III. 12, 344) negando la existencia o providencia de Dios los hombres se desprenden de su tranquilidad pero no de su yugo, afirmación rotunda y significativa que Hobbes emplea para dejar sentado que todos los seres están sometidos a Dios: piedras, plantas, animales y el mismo hombre.

41-80); para una comprensión de la doctrina política cristiano-medieval, ver la obra de M. García-Pelayo, El Reino de Dios, Arquetipo Político (Madrid: Revista de Occidente, 1959). 
Mas la traducción es problemática pues aparece contradictorio el perder la tranquilidad y encima seguir bajo su yugo - ¿qué gana entonces el ateo? $-{ }^{13}$. Pierden su tranquilidad pero no su yugo, por eso el ateo es insensato. Pero el insensato podría siempre alegar que Dios si existe parece no preocuparse de los hombres, a lo que Hobbes responde:"(...) they who attributing, as they think, ease to God, take from him the care of mankind; take from him his honour: for it takes away men's love, and fear of him; which is the root of honour" (Hobbes, EW II, 356) ${ }^{14}$. En cuyo caso estaríamos hablando de una falta que cometen los deístas que, al atribuirle a Dios falta de cuidado por las cosas humanas, le deshonran porque eliminan las manifestaciones de honor que persiguen obtener algún bien de él: ¿Qué bien podríamos obtener de un Dios indiferente? ¿Qué sentido tendría honrarle? Ciertamente que Hobbes no aparece como un deísta en este sentido. Hobbes va a admitir más adelante que Dios ya no interviene como en aquellos tiempos bíblicos, ya no hay milagros ni profetas y hay que andarse con cuidado frente a quienes dicen hacer milagros o hablar en nombre de Dios; éste sería el deísmo de Hobbes, pero ese es otro tema, volvamos a la discusión sobre el dominio de Dios sobre los hombres, el tema del reino de Dios.

Llamar a este dominio de Dios sobre sus criaturas reino genera un nuevo problema.

El empleo del término reino aquí es el uso metafórico de la palabra, advierte el filósofo (Hobbes, II. 12, 344) ${ }^{15}$. Esta es una afirmación muy importante para entender la posición de Hobbes respecto a la relación entre religión y política en su sistema de ideas. Porque si la expresión reino de Dios es metafórica quiere decir que es una extensión de sentido a partir de un sentido propio, que no podría ser otro que el político, y la aplicación del término reino a Dios y su providencia no sería más que una analogía ${ }^{16}$. Ahora bien, en toda analogía se intenta establecer un parecido entre algo más fácil de percibir y una realidad más difícil de entender. En este parecido hay un núcleo duro, podríamos decir, que ambas entidades, en este caso, el reino de Dios (la providencia divina) y el reino de los hombres (la política), comparten. De esta

13 En la versión latina el sentido queda más claro: Homine divinae potentiae, velint nolint, subjiciuntur; et qui existentiam vel providentiam divinam non agnoscent, non jugum executient, sed propiam ipsorum tranquillitatem (EW III, 255), es decir, los hombres quiéranlo o no, están sometidos al poder divino, y aquellos que su existencia o providencia niegan, no pierden su yugo sino su propia tranquilidad. Por eso la traducción de C. Mellizo de la edición Alianza es bastante buena: "Negando la existencia o la providencia de Dios, podrán quizá sentirse liberados, pero no podrán por ello sacudirse el yugo”.

14 “(...) aquellos que le atribuyen, como creen, despreocupación a Dios, le quitan el cuidado de la humanidad; le quitan el honor: porque le quitan el amor de los hombres y el temor a él; que es la raíz del honor" (Hobbes, EW III, 12, 356).

15 Hobbes, EW III, 12, 344.

16 Es el dominio de Dios sobre sus criaturas el que es llamado reino en sentido metafórico pero es importante hacer notar que después Hobbes, al referirse al reino de Jesucristo, después de su segunda venida, no lo llama reino en un sentido metafórico sino real. Es relevante observar las fluctuaciones del término en Hobbes, porque a veces se refiere al entido metafórico de reino y otras al literal. 
forma, ambos términos de este campo semántico comparten aspectos centrales, pero no algunos aspectos periféricos, marginales, que se pueden dejar de lado, sin alterar la analogía fundamental. Por eso es tan importante comprender qué elementos de ambas entidades constituyen el núcleo duro de esta analogía y cuáles son periféricos, porque toda analogía tiene sus límites más allá de los cuales se torna abusiva y engañosa. Por eso es importante escuchar lo que Hobbes dice respecto al sentido primario del término reino para juzgar si su analogía es apropiada o quizá algo abusiva. El texto clásico de Hobbes sobre el gobierno es el siguiente: For he only is properly said to reign, that governs his subjects by his word, and by promise of rewards to those that obey it, and by threatening them with punishment that obey it not (Hobbes, EW 12, 344) ${ }^{17}$. Éste sería el sentido propio de reino y el núcleo duro de la analogía:

Un reino es una comunidad gobernada por un soberano que por medio de sus palabras manifiesta su voluntad y gobierna a su reino, y que premia a los que le obedecen y castiga a los que no lo hacen ${ }^{18}$.

Ciertamente esta visión tiene un tinte positivista y no muy contractualista, a decir verdad, pero nuestro autor enmienda la plana advirtiendo de un rasgo de todo gobierno legítimo para él, el consentimiento de los súbditos, consentimiento que se basa en la comprensión de las palabras del gobernante y la aceptación del fin o propósito del gobierno que encabeza. En consecuencia, si se toma en cuenta el consentimiento para determinar cuándo un gobierno es legítimo, habría que admitir que en este mundo, el único ser que puede consentir ser gobernado por Dios, es el hombre, ya que: Subjects therefore in the kingdom of God, are not bodies inanimate, nor creatures irrational; because they understand no precepts as his: nor atheists, nor they that believe not that God has any care of the actions of mankind; because they acknowledge no word for his, nor have hope of rewards or fear of his threatenings (Hobbes, EW II, 344). Así, los que han aceptado el reino de Dios (en sus corazones y en sus actos) son sus súbditos, y los que no lo han hecho, sus enemigos.

Sigamos analizando su idea de reino. Si el gobierno de Dios se ejerce por su Palabra, entonces habrá que saber cómo habla Dios a sus súbditos. Está claro que no solo Dios necesita gobernar a sus súbditos por medio de la palabra; cualquier gobernante de este mundo debe hacerlo, ya que la promulgación de las leyes es uno de

17 "Porque solo se dice propiamente que alguien reina cuando gobierna a sus súbditos por su palabra, y por la promesa de premios a aquellos que le obedezcan, y por amenazas de castigos a aquellos que no le obedezcan" (Hobbes, EW III, 12, 344).

18 Ciertamente, esta idea del contrato parece una buena analogía con el contrato bíblico. Pero es discutible que sea el núcleo duro de la analogía, puesto que se deja fuera el consentimiento de los súbditos y el fin moral que el contrato bíblico tiene, enfatizando solo el poder absoluto del soberano y la obediencia total de los súbditos. Si bien el cristianismo de Hobbes aparece como judaizante por esta idea del poder absoluto y la sumisión total, tal apariencia es discutible y la vamos a discutir posteriormente (Cfr. Elazar, David, J. (ed.), Jewish Political Studies Review. Thomas Hobbes Confronts the Bible. Vol. 4, No 2. Fall, 1992). 
sus requisitos fundamentales para darlas a conocer y evitar la ignorancia como excusa para no cumplirlas. ¿Pero cómo habla Dios entonces a sus súbditos? Por tres medios a su disposición, la razón natural, la revelación y la voz de los profetas:

(...) God declareth his laws three ways; by the dictate of natural reason, by revelation, and by the voice of some man, to whom by the operation of miracles, he procureth credit with the rest. From hence there ariseth a triple word of God, rational, sensible, and prophetic: to which correspondeth a triple hearing; right reason, sense supernatural, and faith ( Hobbes, EW III, 345).

Hobbes, como se ve, atribuye gran importancia a la fe y a la razón como manifestaciones de la palabra de Dios, pero parece encontrar cierta dificultad en determinar el valor del sentido sobrenatural: la razón es universal, la fe también, pero el sentido sobrenatural, lo que las personas dicen haber recibido por inspiración divina o en sueños, le parece al filósofo inglés discutible: ¿Cómo tener fe en personas que se atribuyen hablar con Dios sin dar ninguna prueba que lo demuestre? Y más aún por lo particular y variado de estos mensajes divinos: ¿Cómo confiar en lo que dicen quienes declaran haber hablado con Dios? La situación planteada es fundamental para un paso que Hobbes va a dar con respecto al pueblo elegido, los judíos. Pero no nos adelantemos, y prestemos atención a lo que dice:

From the difference between the other two kinds of God's word, rational, and prophetic, there may be attributed to God, a twofold kingdom, natural, and prophetic: natural, wherein he goberneth as many as acknowledge his providence, by the natural dictates of right reason; and prophetic, wherein having chosen out one peculiar nation, the Jews, for his subjects, he governed them, and none but them, not only by natural reason, but by positive laws, which he gave them by the mouths of his holy prophets (Hobbes $E W$ II, 345).

Esta elección de Dios del pueblo judío, y de nadie más que ellos, tiene para Hobbes como consecuencia que solo en este caso, se da un gobierno doble, es decir, dirigido por la palabra natural (la recta razón), y la palabra profética (la ley de Dios), ley expresada por medio de profetas verdaderos. No cualquier persona que se atribuya el poder hablar con Dios o en nombre de Dios es un profeta verdadero, sino que solamente aquellos profetas que exhiben las pruebas de su elección divina, la realización de milagros principalmente. Para todos los otros pueblos solo queda la razón natural como medio para conducir a una nación por el buen camino.

En consecuencia, una república cristiana pertenece al reino natural de Dios y por eso debe regirse por la razón natural, que por ser natural proviene, como todas las cosas, en última instancia, de Dios como causa prima; lo único diferente aquí con respecto a las otras naciones sería que cualquier otra nación que no sea la judía no ha pactado con Dios mismo, y no es gobernada entonces por su palabra profética. Habiendo hecho esta diferencia entre: $1^{\circ}$ el pueblo judío gobernado por la palabra de Dios y la razón natural y $2^{\circ}$ los pueblos comunes gobernados solo por la razón natural, cabe hacer otra distinción en este plano, entre los pueblos cristianos que pueden consentir ser una república cristiana y los pueblos nocristianos que no pueden consentir en ser una 
república cristiana porque no han recibido la Palabra, y que por su misma ignorancia son inocentes de tal pecado, como los indios de la América poscolombina que eran, para los teólogos hispanos, inocentes, impíos pero no infieles, pero que luego que los conquistadores les leían el requerimiento, ya no eran tan inocentes, y menos aún si aceptaban ser bautizados, ya que en caso de rebelión se les podía hacer la guerra justa como infieles. Pero volviendo al plano filosófico, si nos concentramos solo en los pueblos cristianos, podría darse una república cristiana que imite el gobierno de Dios, y eso es lo que al parecer, intenta hacer Hobbes por todo lo ya visto; esto es, establecer una analogía entre el poder de Dios y el poder de un soberano terrenal. De esta manera, para evaluar lo apropiado de esta analogía habrá entonces que comparar el gobierno de Dios con el gobierno de los hombres. Para eso nos vamos a remitir a 2: 31 en lo que concierne al derecho (right) que Dios tiene de gobernar el cielo y la tierra, para luego entender la similitud que Hobbes establece entre el derecho divino y el humano.

Este gobierno divino es, en el caso de las naciones cristianas, un gobierno de Dios por naturaleza, por medio de las causas segundas, podríamos decir. En este contexto, el derecho de Dios, su derecho natural, es definido por Hobbes de una manera peculiar "The right of nature, where by God reigneth over men, and punisheth those that break his laws, is to be derived, not from his creating them, as if he required obedience as for gratitud for his benefits; but from his irresistible power" (Hobbes, EW. 12, 345). Esta manera de entender la relación de Dios con los hombres es discutible, no por ser falsa, Dios es todopoderoso, sino porque el poder es solo uno de sus atributos, una de sus excelencias. Por eso, la visión de Hobbes aparece no como errada, pero quizás como insuficiente o reductora. Considérese solo una cuestión justamente de principios: la tradición cristiana sostiene que el acto creador de Dios es por esencia un acto de amor, y el amor no espera nada más que gratitud, la lógica retribución por los bienes recibidos: Dios es amor y si se deja afuera este aspecto tan principial, quizás la analogía esté yendo demasiado lejos. No obstante, Hobbes prefiere distanciarse, por ahora, de esta afirmación dogmática, a la que volverá más tarde, aunque en forma algo tangencial, y resaltar que Dios es más bien un gobernante todopoderoso al que siempre se le obedece porque es inútil resistírsele. Justamente ésta es la tesis que sostiene Foisneau (2000) en la cual no solo se demuestra que éste parece ser un rasgo central de la teología de Hobbes, sino que, además, le aporta dos aspectos esenciales a su filosofía política:

Dios es todopoderoso, puede hacer todo, pero también puede hacer todo lo que quiere, su voluntad es poder y no hay distancia entre lo que Dios quiere y lo que puede; de esta manera tanto el absolutismo como el voluntarismo encuentran en el cristianismo una justificación del poder absoluto de los gobernantes, el establecimiento del Leviatán, el dios moral a la espera del dios inmortal al final de los tiempos.

Es cierto que ésta es una visión más bien vetero-testamentaria que neo-testamentaria, pero aun así, es discutible que Hobbes pueda dejar de lado la gloria de Dios o la gratitud debida a Dios como la forma más sutil que tiene Dios de actuar en las personas de acuerdo a su misma naturaleza, lo que supone, a su vez, la gratitud como una conducta lógica ante los bienes recibidos, aunque muchas veces lamentablemente las personas sean ingratas. 
Pero, hasta aquí, ésta es su manera de ver el tema, y el poder irresistible de Dios es su paradigma, al punto que cuando compara al gobierno de los hombres con el gobierno de Dios, la analogía le sirve para demostrar: $1^{\circ}$ Cuán grande es su poder y $2^{\circ}$ Que su poder es irresistible. Atiéndase a esta comparación:

I have formerly shown, how the sovereign right ariseth from pact: to show how the same right may arise from nature, requiereth no more, but to show in what case it is never taken away. Seeing all men by nature had right to all things, they had right every one to reign over the rest. But because this right could not be obtain by force, it concerned the safety of every one, laying by that right, to set up men, with sovereign authority, by common consent, to rule and defend them ... (Hobbes, $E W 12,346)$.

Ésta es una reformulación de su doctrina del pacto social como origen del estado y ciertamente no contiene nada nuevo; el consentimiento de los hombres es el origen de la designación de una persona o reunión de personas, como le gusta decir a Hobbes, para que ésta gobierne y proteja a cada uno de los firmantes del pacto.

Dicho pacto, sin embargo, requiere permanencia en el tiempo, y eso, a su vez, depende de que los hombres lo sigan manteniendo, cumpliendo el pacto, como un medio para alcanzar la paz. No obstante, aquí surge un problema, un poder humano de estas características, que tiene su origen en un contrato social, que implica el consentimiento de cada uno de los pactantes, es, como todo contrato, nulo, sin el poder de las armas, sin un gobernante autorizado para hacer uso de su poder para hacer cumplir este pacto (covenant), ya que si no lo hace, y los hombres ven que es más ventajoso no cumplir los pactos, ciertamente lo harán.

Por lo tanto el poder del soberano es absolutamente necesario para mantener y hacer cumplir los pactos.

Ahora bien, teóricamente, según nuestro pensador, mientras más poder tenga un gobernante, más fácil le será el mantener el pacto social y mientras menos poder tenga, más difícil será, para él, mantenerlo; eso es lo que Hobbes deduce, no más de ver lo que sucede en la Inglaterra de Carlos I y que él expresa en el Behemot, siendo la debilidad del rey una de las causas de la guerra civil. Por eso no es raro que piense que si un gobernante tuviera un poder absoluto, como el de Dios, no tendría dificultad alguna para mantener el pacto, y además, su palabra sería ley y sus acciones justas solo por su imperio: por eso la analogía con el poder de Dios concuerda con su filosofía política. Pero prestemos atención a lo que dice:

(...) whereas if there had been any man of power irresistible, there had been no reason, why he should not by that power have ruled and defended both himself, and them, according to his own discretion. To those therefore whose power is irresistible, the dominion of all men adhereth naturally by their excellence of power; and consequently it is from that power, that the kingdom over men, and the right of afflicting men at his pleasure, belongeth naturally to God Almighty; not as Creator, and gracious; but as omnipotent (Hobbes, EW III. 12, 346). 
Un hombre con poderes irresistibles sería obedecido por todos, no tendría, teóricamente, problemas para mantener la salud y la continuidad del estado. Ciertamente que esto no es todo el problema político, $\mathrm{y}$, además, sabemos que es peligroso que algunos hombres tengan tal poder; aunque sea interesante teóricamente admitir que un gobernante tal como el descrito por Hobbes sería irresistible, y sus acciones serían justas por la pura "excelencia de su poder", no ciertamente por los fines que persigan, o la razón por la cual se ejecuten, y finalmente sería cierto que might is right.

Siendo este punto tan importante en Hobbes, el filósofo deberá esforzarse por demostrar que el poder de Dios es absoluto, que reina más allá del bien y del mal, de lo justo o de lo injusto, porque sus designios son misteriosos y todo intento por descubrir a Dios en la experiencia diaria están condenados al fracaso. La realidad es muchas veces injusta y cruel y lo único que le queda al hombre es el sometimiento a la voluntad de Dios. Así, la prueba que Hobbes exhibe del irresistible poder de Dios es que los castigos divinos no son siempre el castigo de nuestros pecados. Históricamente siempre ha llamado la atención el porqué los malos prosperan en este mundo y los buenos no lo hacen, situación que Hobbes explica mediante el poder de Dios, al cual parece no importarle la justicia de sus actos, justicia terrenal, por supuesto, ya que lo que hace Dios es justo solo porque lo impone con su irresistible poder, ya que "(...) the right of afflicting, is not always derived from men'sins, but from God's power" (el derecho de infligir daño o penas no se deriva siempre de los pecados de los hombres, sino del poder de Dios). Y el mejor ejemplo que Hobbes encuentra en la Biblia es el del Libro de Job.

\section{3.- Conclusión}

Si bien el reino de Dios no es de este mundo, incluso hablar de "reino" sería hacer uso de un símbolo, en cuyo caso siempre hay una parte de verdad y una parte de ficción que apunta a una referencia no expresable. Sin embargo, pensamos que Hobbes entiende que el reino de Dios será un verdadero reino solo al final de los tiempos. Por lo mismo, mientras esperamos aquí en la tierra la venida de este verdadero reino de Dios, no podemos más que aceptar a manera de un deus mortalis, al Leviatán, el gobierno absoluto dueño del poder temporal pero también del espiritual, mientras esperamos la segunda venida de Cristo: ¿Es esto una secuencia, una suerte de genealogía? Hubo ingleses que creyeron ser descendientes de Abraham, ¿o es simplemente la actualización que Hobbes hace de un ideal político que él ve realizado en las Escrituras? O como creemos es el uso abusivo de textos bíblicos para sus propios fines políticos lo que ha dado pie a la acusación de insinceridad de parte de Hobbes, quien haría uso de textos bíblicos ad-hoc para probar sus tesis políticas.

Creemos que se puede ser sincero y creer, como lo hace Hobbes, que lo que expresa es realmente verdadero, que sus ideas corresponden a las Escrituras. Pero esto no es ápice para que esté errado en su interpretación del mensaje bíblico, o que su visión del cristianismo sea minimalista, que es lo que hemos tratado de demostrar en otros artículos. Esto en gran parte por desconocer aspectos bíblicos, como su lenguaje y lógica a la que nos 
hemos referido antes, lo que genera un problema hermenéutico del que Hobbes, no estamos seguros, sea culpable porque es posible que hoy sepamos más sobre este tema que en su época, lo que suele suceder en la interpretación de los clásicos.

Con todo eso, la relación entre religión y política ha ido adquiriendo una importancia mayor a la luz de problemas político-religiosos que nos obligan a preguntarnos por esta relación como algo que no es solo un lujo intelectual. Por eso mismo hay que volver a Hobbes porque un abuso de la religión puede llevar a serios problemas políticos. Thomas Hobbes puede ser un caso de un pensador muy racional, pero cuya visión de la religión no es todo lo buena, ajustada y correcta que uno esperaría, justamente porque la religión no es solo la obediencia a la ley, y el temor a la misma no es necesariamente el origen del internal ought ${ }^{19}$ de la acción moral.

\section{Referencias bibliográficas}

Allen, W. (2004), The Two and the Many: Or, Love and Polítics. Modern Age.

Darwall, S. (1995), The British Moralists and the Internal Ought 1640-1740. Cambridge University Press.

De Coulanges, F. (1864/2012), La Ciudad Antigua. México: Editorial Porrúa.

Deigh, J. (1996), Reason and ethics in Hobbes's Leviathan. Journal of the History of Philosophy 34 (1), 33-60.

D’ors, A. (1976), Teología Política: una revisión del problema. Revista de estudios políticos $\mathrm{N}^{\mathrm{o}} 205,41-80$ ).

Elazar, D. J. (2000), Covenant and Community. Judaism. New York. Vol. 49, Iss. 4, 387-399.

(1997), Covenant as a Political Concept. The Covenant Tradition in Politics, Volumen 1, Chapter 1, Transactio Publishers.

(1992), Hobbes Confronts Scripture. Jewish Political Sudies Review, Vol. $4, \mathrm{~N}^{\circ} 2$.

García-Pelayo, M. (1959), El Reino de Dios, Arquetipo Político (Estudio sobre las Formas Políticas de la Alta Edad Media). Madrid: Revista de Occidente.

Hoekstra, K. (2003), Hobbes on law, nature, and reason. Journal of the History of Philosophy, Vol. 41, 111, 121.

Hobbes, T. (1966), The English Works of Thomas Hobbes III. Sir William Molesworth, Bart (ed.). Scientia Verlag Aalen, Germany, 1966.

(1994), Letter 42, Hobbes to Samuel Sorbiere, from Paris, 22 May/1 June 1646. Thomas Hobbes. The Correspondence. Malcolm, N. (ed.). Vol. 1. Oxford: Oxford Claredon Press.

19 Cfr. Stephen Darwall, The British Moralists and the Internal Ought 1640-1740 (Cambridge University Press, 1995). 
Hood, F. C. (1964), The Divine Politics of Thomas Hobbes. Oxford: Claredon Press. Murphy, M. (2000), Desire and ethics in Hobbes's Leviathan: A response to professor Deigh. Journal of the History of Philosophy 38, 2; ProQuest Humanities, 259268.

Ratzinger, J. Benedicto XVI. (2007), Jesús de Nazaret. Bogotá: Planeta.

Touchard, J. (1987), Historia de las Ideas Políticas. Madrid: Tecnos. 